\title{
PHENOMENON OF TECHNOLOGICAL UNEMPLOYMENT: INEVITABILITY OF TRANSFORMATION OF SOCIO-ECONOMIC RELATIONS
}

\author{
Azamat B. Berberov \\ Financial University under the Government of the Russian Federation, Moscow, Russian Federation
}

\begin{abstract}
This article is aimed at studying the prospects for the development of social and economic relations in the context of forming digital economy and potential growth of technological unemployment. To achieve this goal, the article provides a retrospective analysis of works of various representatives of domestic and foreign economic schools, as well as proposals of the International Labor Organization and the Organization for Economic Cooperation and Development (OECD). Judging by the results of the first part of the study, international institutions attempt to improve social and economic relations in a coordinated manner due to the fact that the rapid development of digital economy can have ambiguous consequences. However, the analysis shows that such actions are likely to be ineffective because of the unique characteristics of states. The second part of the study is aimed at studying the role and position of the Russian Federation in this process. For this purpose, the author carries out a chronological analysis of social and labor relations starting with the period of the Russian Empire and ending with modern Russia in the context of the phenomenon of technological unemployment. The results of the primary research indicate that, due to the unique socio-economic characteristics, technological unemployment was not a dominant feature of the Russian reality. However, a more detailed analysis based on specific empirical data allows us to identify the facts of technological displacement of the labor force, as well as describe the level of social and labor relations in the Russian Empire in the pre-revolutionary period. Based on the results obtained in the first and second parts of the study the author tries to give an objective description of the peculiarities of social and labor relations in the modern Russian Federation in the context of the potential growth of technological unemployment. The current economic picture points to the high risks of technological unemployment in the Russian Federation and updates the adoption of urgent measures to design improved social and labor relations in the Russian Federation.
\end{abstract}

Key words: technological unemployment, social and labor relations, digital economy, capitalism, Russian Federation.

Citation. Berberov A.B. Phenomenon of Technological Unemployment: Inevitability of Transformation of Socio-Economic Relations. Journal of Volgograd State University. Economics, 2019, vol. 21, no. 3, pp. 36-47. (in Russian). DOI: https://doi.org/10.15688/ek.jvolsu.2019.3.4

УДК 331.1

Дата поступления статьи: 26.06.2019

ББК 65.24 Дата принятия статьи: 15.07.2019

\section{ФЕНОМЕН ТЕХНОЛОГИЧЕСКОЙ БЕЗРАБОТИЦЫ: НЕИЗБЕЖНОСТЬ ТРАНСФОРМАЦИИ СОЦИАЛЬНО-ЭКОНОМИЧЕСКИХ ОТНОШЕНИЙ}


организации труда и Организации экономического сотрудничества и развития (ОЭСР). Судя по результатам первой части исследования, в связи с тем, что бурное развитие цифровой экономики может нести за собой неоднозначные последствия, международными институтами предпринимаются попытки по координированному совершенствованию социально-экономических отношений. Как показывает анализ, такие действия, вероятно, будут иметь низкую эффективность в силу наличия у государств уникальных характеристик. Вторая часть исследования направлена на изучение роли и позиции Российской Федерации в данном процессе. Для этого автором проводится хронологический анализ социально-трудовых отношений, начиная с периода Российской империи и заканчивая современной Россией, в контексте феномена технологической безработицы. Результаты первичного исследования указывают на то, что в силу наличия уникальных социально-экономических характеристик технологическая безработица не была доминантной чертой российской действительности. Однако более детальный анализ, основанный на конкретных эмпирических данных, позволяет выявить факты технологического вытеснения рабочей силы, а также описать уровень социально-трудовых отношений в Российской империи дореволюционного периода. Отталкиваясь от полученных результатов в первой и второй частях исследования, автор пытается дать объективную характеристику особенностям социально-трудовых отношений в современной России в контексте потенциального роста технологической безработицы. Сложившаяся экономическая картина указывает на высокие риски технологической безработицы и актуализирует принятие безотлагательных мер по проектированию усовершенствованных социально-трудовых отношений в Российской Федерации.

Ключевые слова: технологическая безработица, социально-трудовые отношения, цифровая экономика, капитализм, Российская Федерация.

Цитирование. Берберов А. Б. Феномен технологической безработицы: неизбежность трансформации социально-экономических отношений // Вестник Волгоградского государственного университета. Экономика. -2019. - Т. 21, № 3. - C. 36-47. -DOI: https://doi.org/10.15688/ek.jvolsu.2019.3.4

\section{Введение}

Исследование негативных последствий взаимодействия техники и человека имеет достаточно длительную научную историю. Проблема их смягчения или устранения не дает покоя умам многих поколений и является предметом ожесточенных споров между представителями различных слоев обществ, прежде всего теми, чьи интересы в большей степени затрагиваются внедрением новой техники, а именно рабочими и предпринимателями. Одной из таких застарелых, трансисторических проблем является технологическая безработица, возникающая в силу «внезапного преобразования техники производства», «вытеснения рабочих из их прежних занятий в силу технологических изменений без предоставления никакого нового», «устранения некоторых старых специальностей в силу технического прогресса» и т. д. [Смирнов, 1969, с. 101].

Как в свое время отмечал немецкий экономист и философ Карл Маркс (1818-1883), сами по себе машины «не ответственны за то, что они “освобождают” рабочего от жизненных средств» [Маркс, 1983, с. 401]. Причиной безработицы является не сам по себе технический прогресс, а особенности капита- листической системы производственных отношений, среди них: относительное уменьшение спроса на рабочую силу в результате органического строения капитала, а также, безусловно, целевая направленность предпринимателя только на увеличение собственной прибыли и низкий уровень социальной ответственности работодателя перед работником [Смирнов, 1969, с. 101].

Из представленных особенностей формируется и другое важнейшее противоречие современного капитализма. С одной стороны, содействие в смене профессии и получении более высокой квалификации требует значительных финансовых затрат и существенной поддержки со стороны компании или государства. С другой стороны, в условиях капитализма не представляется возможной планомерная переподготовка «технологически высвобожденных» работников в силу наличия диспропорций в спросе и предложении рабочей силы. И даже если применение машины ведет к увеличению спроса и расширению производства, то не всегда такое расширение бывает пропорционально количеству вытесненной рабочей силы и наступает оно не сразу. Вследствие чего смена технологического уклада может являться как време- 
нем страданий для рабочего класса, так и тяжелым периодом для экономики: введение техники, ведущее к увеличению производства, но сокращающее личное потребление работника, может привести к ее коллапсу [Чупров, 1916, с. 223].

В этих условиях особое значение обретает уровень «сплоченности» рабочего класса. Как справедливо отмечает российский экономист М.И. Туган-Барановский (18651919), «доля общественного продукта, поступающая в пользу капиталистов, определяется при прочих равных условиях социальной мощью капиталистического класса» [Туган-Барановский, 1903, с. 399]. Связано это с тем, что обе стороны - рабочий класс и капиталисты - стремятся захватить в свою пользу как можно больше общественного продукта. В случае если рабочий класс не организован, капиталисты являются стороной-победителем, которой поступает практически вся часть общественного продукта, за исключением объема средств, достаточных для минимального существования рабочего [Туган-Барановский, 1903, с. 400].

Гораздо более радикальную оценку взаимоотношениям рабочего класса и капиталистов дает финский теоретик марксизма Отто Куусинен (1881-1964). Так, выступая в 1929 г. на Х пленуме Исполнительного комитета Коммунистического интернационала, он указывает на наличие у класса капиталистов или крупнейших магнатов капитала требования (хотя и утопического) освободить «от всякой зависимости от пролетариата собственной страны и, несмотря на это, быть в состоянии все более увеличивать прибыль» [Империализм ..., 1931, с. 80]. По мнению политического деятеля, такая социально-экономическая система являлась бы идеальным состоянием капитализма (как на Ривьере или в Монако) и «заманчивой перспективой» в силу постоянного уменьшения числа рабочих при увеличивающейся прибыли без опасности революции [Империализм ..., , 1931, с. 80].

Таким образом, в условиях капиталистической формы хозяйствования развитие производственных отношений внутри рабочего класса (например, в форме поддержания профсоюзов, нового общественного контракта) становится одним из важнейших инструментов разрешения противоречий. В частности, по мнению советского исследователя А. Кузнецова, в случае введения машины в производство профессиональный союз не должен бороться против новой техники, а, скорее, должен предпринимать попытки по сохранению прежнего уровня заработной платы [Кузнецов, 1929, с. 132]. Данное предложение, по сути, повторяет компромиссную доктрину, изложенную еще в XIX в. британским экономистом Джеймсом Сиднеем Вэббом, о том, что «споры не должны идти о том, следует ли вводить машины, а должны лишь идти о том, на каких условиях их вводить» (цит. по: [Колокольников, 1909, с. 41]).

\section{Развитие}

\section{социально-экономических отношений:} Вызовы цифровой экономики

В странах Запада после окончания Второй мировой войны резко возросла роль регулирования социально-трудовых отношений. Как отмечает российский экономист В.А. Красильщиков, это связано с развитием поточно-конвейерного производства и укреплением общедемократического движения. В таких условиях предпринимателю выгоднее уступить требованиям профсоюза рабочих, нежели допустить остановку конвейера. Однако такая ситуация стимулирует компанию к внедрению новой техники, которая бы снижала совокупные издержки, в том числе и на труд [Красильщиков, 1998, с. 70].

В условиях, когда внедрение техники само по себе не ведет к увеличению занятости, профсоюзами все чаще ставится вопрос о приоритете интересов трудящихся, а не увеличения прибыли при модернизации производства. Например, в коллективные договоры стали включать требование профсоюзов о том, чтобы переподготовка высвободившихся в силу технического прогресса работников шла за счет предприятия при полном сохранении их зарплаты, а в случае невозможности сохранения того же количества работников обеспечить их денежными пособиями по безработице [Макушина, 2011, с. 243].

Таким образом, деятельность профсоюзов и другие инструменты, направленные на регулирование социально-трудовых отношений, 
становятся важными составляющими научнотехнического прогресса. Их наличие в сотрудничестве с правительством и работодателями способствует созданию новых рабочих мест, а также обеспечивает заботу о тех представителях рабочего класса, которые являются наиболее уязвимыми в переломный период становления нового технологического уклада.

Приведенные постулаты приобретают новый облик актуальности сегодня. Как отмечает Международная организация труда (далее - МОТ) в одном из своих докладов, «сфера труда преобразуется под воздействием новых сил» в связи с технологическими достижениями. Такая трансформация будет вести к созданию новых рабочих мест, но проблема в том, что профессиональные компетенции, которые являются конкурентоспособными сегодня, могут устареть в ближайшее время. Однако Международная организация придерживается оптимистического взгляда на данную проблему, признавая тот факт, что возможности, открываемые техническим прогрессом, способны построить лучшее будущее, обеспечить экономическую стабильность и т. д. [Работать ...].

Ключевым инструментом осуществления планомерных и плавных преобразований является новая повестка дня, ориентированная на человека, где особое место займет новый общественный договор, наличие которого позволит работникам получать «справедливую долю экономического прогресса, уважение их прав и защиту от рисков в обмен на их дальнейший вклад в развитие экономики» [Работать ...]. Рекомендации МОТ предусматривают три основных направления действий, однако в контексте нашего исследования следует выделить следующие конкретные предлагаемые меры, имплементация которых позволит более «безболезненно» войти в новый технологический уклад [Работать ...]:

- увеличить инвестиции в учреждения, политику и стратегии, которые будут поддерживать людей во время переходных процессов в будущей сфере труда;

- обеспечить коллективное представительство работников и работодателей посредством социального диалога как общественного блага при активном содействии со стороны государственной политики;
- внедрять и применять технологии в интересах достойного труда.

Признавая неотвратимость рисков от становления цифровой экономики, 36 стран ОЭСР и государства-партнеры в конце мая приняли первый набор руководящих принципов ОЭСР в области искусственного интеллекта, предусматривающих соблюдение странами-подписантами международных стандартов, направленных на обеспечение надежности, безопасности и справедливости при использовании искусственного интеллекта. Данный документ призван служить руководством для правительств, организаций и отдельных лиц при разработке и эксплуатации систем искусственного интеллекта [Forty-two countries ...].

В самом начале данного документа генеральный секретарь ОЭСР Анхель Гурриа отмечает, что «искусственный интеллект революционизирует наш образ жизни и работы и приносит огромную пользу обществу и экономике» [Forty-two countries ...]. Однако его внедрение «создает новые проблемы, усиливает тревогу и порождает новые этические проблемы», что возлагает на правительства обязанность по обеспечению того, чтобы системы искусственного интеллекта разрабатывались с учетом общепринятых ценностей и законов, с тем чтобы люди могли быть уверены, что их безопасность и конфиденциальность будут иметь первостепенное значение [Forty-two countries ...]. Отдельное место в озвученных принципах уделяется устранению потенциальных рисков технологической безработицы. Так, пункт 2.4 документа предусматривает следующие рекомендации для правительств государств [Recommendation ...]:

- обеспечение тесного сотрудничества с заинтересованными сторонами для подготовки к преобразованиям мира труда и общества. Правительства должны дать людям возможность эффективно использовать системы искусственного интеллекта и взаимодействовать с ними по всему спектру применений, в том числе путем обучения их необходимым навыкам;

- принятие шагов, в том числе в рамках социального диалога, направленных на обеспечение справедливого перехода трудящихся по мере развертывания искусственного интеллекта, например посредством про- 
грамм профессиональной подготовки на протяжении всей трудовой жизни, оказания поддержки лицам, пострадавшим от замещения, и обеспечения доступа к новым возможностям на рынке труда;

- обеспечение тесного сотрудничества с заинтересованными сторонами в целях поощрения ответственного использования искусственного интеллекта на работе, повышения безопасности работников и качества рабочих мест, поощрения предпринимательства, повышения производительности и обеспечения широкого и справедливого распределения выгод от искусственного интеллекта.

Безусловно, данное соглашение является шагом вперед на пути к «очеловечиванию» социально-трудовых отношений и выстраиванию справедливых «правил игры» в условиях новой технологической эпохи. Следует отметить, оно концептуально связано с утопическим предложением голландского профсоюзного деятеля Эдо Фиммена (1881-1942) заключить международное соглашение о «замедлении применения новых методов производства» [Фиммен, 1924, с. 29]. Однако вряд ли можно пока утверждать, что инициатива ОЭСР при- ведет к плавности перехода глобального общества к новому технологическому укладу. Во-первых, данный документ носит сугубо рекомендательный характер. Во-вторых, в состав участников не входят другие государства, такие как Китай, Индия, Российская Федерация и т. д. В-третьих, текущий состав участников соглашения представляется крайне неоднородным, что проявляется при анализе социально-экономических характеристик государств.

В таблице 1 отражены два показателя. Первый показатель - отношение объема затрат на R\&D к BBП, которое могло бы указывать место страны на технологической карте мира. Второй показатель - уровень нарушения трудовых прав, отражающий положение рабочего класса в государстве, согласно данным Международной конфедерации профсоюзов.

Результаты анализа указывают на то, что среди наиболее технологически «гармоничных» юрисдикций выделяются Австрия, Швеция, Израиль, Япония и Швейцария. Для названных государств характерен высокий уровень R\&D-затрат к BBП в совокупности с

Межстрановое сравнение показателей $R \& D / B B \Pi$

Таблица 1

и уровня защиты трудовых прав населения

\begin{tabular}{|c|c|c|c|c|c|}
\hline \multirow{2}{*}{$\mathrm{R} \& \mathrm{D} / \mathrm{BB \Pi}$} & \multicolumn{5}{|c|}{ Показатель уровня нарушения трудовых прав } \\
\hline & 1 & 2 & 3 & 4 & 5 \\
\hline$(0-1 \%)$ & Словакия & $\begin{array}{l}\text { Литва, } \\
\text { Коста-Рика, } \\
\text { Латвия }\end{array}$ & Польша & $\begin{array}{l}\text { Аргентина, } \\
\text { Мексика, } \\
\text { Румыния, } \\
\text { Чили, } \\
\text { Перу }\end{array}$ & $\begin{array}{l}\text { Турция, } \\
\text { Колумбия }\end{array}$ \\
\hline$(1-2 \%)$ & $\begin{array}{l}\text { Италия, } \\
\text { Ирландия }\end{array}$ & $\begin{array}{l}\text { Чехия, } \\
\text { Эстония, } \\
\text { Португалия, } \\
\text { Новая Зеландия } \\
\end{array}$ & $\begin{array}{l}\text { Австралия, } \\
\text { Великобритания, } \\
\text { Венгрия, } \\
\text { Испания } \\
\end{array}$ & - & $\begin{array}{l}\text { Бразилия, } \\
\text { Греция }\end{array}$ \\
\hline$(2-3 \%)$ & $\begin{array}{l}\text { Германия, } \\
\text { Дания, } \\
\text { Финляндия, } \\
\text { Исландия, } \\
\text { Нидерланды, } \\
\text { Норвегия }\end{array}$ & $\begin{array}{l}\text { Бельгия, } \\
\text { Франция }\end{array}$ & - & США & - \\
\hline$(3-4 \%)$ & $\begin{array}{l}\text { Австрия, } \\
\text { Швеция }\end{array}$ & \begin{tabular}{|l|} 
Япония, \\
Швейцария
\end{tabular} & Канада & - & - \\
\hline$>4 \%$ & - & Израиль & - & - & Корея \\
\hline
\end{tabular}

Примечание. Составлено автором. Показатель уровня нарушения трудовых прав определялся по: [Report ...], где 1 - «единичные случаи нарушений», ..., 5 - «отсутствие гарантии на соблюдение трудовых прав». Значение R\&D/BВП определялось по: [Research ...]. 
высоким уровнем защиты трудовых прав. Сразу 7 стран попали в зону высокого риска (Аргентина, Мексика, Румыния, Чили, Перу, Турция и Колумбия), для них характерно низкоеучастие в R\&D-исследованиях и низкий уровень защиты трудовых прав. Очевидно, что для этих стран рецепт перехода к новому технологическому укладу будет несколько другим, нежели для государств с высокими уровнями $\mathrm{R} \& \mathrm{D}$-затрат к BBП и защиты трудовых прав.

\section{Социально-экономические отношения в Российской Федерации и проблема технологической безработицы}

Особый интерес в данном контексте представляет позиция Российской Федерации. С одной стороны, исторически российское государство не было активным пользователем трудосберегающих технологий (возможно, за исключением периода существования СССР) в силу низкого уровня заработных плат [Богданов, 1923, с. 116]. Об этом также свидетельствуют статистические данные, которые приводит в одной из своих работ русский экономист С.И. Гулишамбаров (1849-1915), касаясь вопроса о количестве паровых двигателей в некоторых западноевропейских странах. По его словам, на Россию приходилось около $8 \%$ от совокупного количества мирового населения и $5,02 \%$ от общего объема тысяч «паровых лошадей». Сравнение отечественных данных с аналогичными показателями для других стран может указывать на технологическую отсталость российского государства. Например, в то же время на США приходилось около $4,35 \%$ от общего количества мирового населения, тогда как «паровых лошадей» было несравнимо больше - 30,48 \% от их совокупного объема [Гулишамбаров, 1907, с. 11].

С другой стороны, исследование отечественных источников указывает на то, что процесс вытеснения рабочей силы в силу технического прогресса (хотя и не катастрофический) в российском государстве имел место. Например, в «Наказах» Екатерины II отмечается, что «махины, которые служат к сокращению рукоделия, не всегда бывают полезны», так как при определенных условиях могут сокращать рукоделие и уменьшать число рабочих [Наказ ..., 1767, с. 73].
Анализ информации из сборника «Фабрично-заводская промышленность и торговля России» (1893) указывает на двукратное увеличение производства изделий писчебумажной отрасли за период с 1862 по 1881 г. при снижении количества работников на $12 \%$. Как подчеркивают авторы сборника, данный период характеризуется введением в практику машинной выделки бумажного листа взамен ручной, и, на наш взгляд, это же являлось причиной вытеснения человеческой рабочей силы [Фабрично-заводская промышленность ..., 1893, с. 78]. На рубеже XIX-ХХ вв. и российские бурлаки стали жертвой технологической безработицы, обусловленной «машинами», то есть речными пароходами, которые, естественно, привели к «десакрализации» человеческой деятельности. Русский общественный деятель и меценат Л.А. Тихомиров (1852-1923) в своих воспоминаниях о встрече с бурлаками отмечает, что «с первых же слов разговор с ними переходил на отсутствие работы, на крайнюю бедность», а ненависть к предпринимателям и хозяевам новых машин обыкновенно слышалась повсюду [Тихомиров, 1907, c. 52].

Однако начало нового века отмечено знаком трансформации социально-трудовых отношений между работодателем и рабочим классом в Российской империи. Профсоюзные организации считают своим долгом встать на защиту рабочего человека «от деструктивной агрессии машины» и разрабатывают систему конкретных мер по учету интересов рабочих при внедрении новых инженерных технологий. Профсоюзные «заступники» признают, что остановить историческое время невозможно, вследствие чего все свои силы они направляют на максимально безболезненную адаптацию человека к новому технологическому миропорядку. Вот характерный отрывок из постановления Петербургского Союза печатников: «Союз берет под свой контроль поступление на машины, также и обучение на машинах, причем при поступлении на машины отдается предпочтение рабочим, выброшенным на улицу, благодаря их введению» (цит. по: [Балабанов, 1927, с. 67]). Московской областной конференцией текстильных рабочих было предложено следующее: «Рабочие, лишающиеся прежней работы с введением новых ма- 
шин и процессов производства, должны получить работу в тех же или других отделах фабрики» (цит. по: [Балабанов, 1927, с. 67]).

Зафиксированы и другие меры социальной защиты интересов работников, среди них уведомление союза текстильщиков за два месяца до введения новых машин и процессов производства [Колокольников, 1909, с. 50]. Такой отрезок «временной благотворительности» давал увольняемым работникам возможность оправиться от социального шока при извещении об истечении контракта и без панического страха заняться задачами трудоустройства на новом месте. В отдельных случаях профессиональными союзами выдвигается условие о выплате двух или трехмесячного пособия вытесненным машиной рабочим. Конечно, такая форма социальной инициативы работодателям кажется излишеством и вызывает опротестование. Ярким тому примером является статья в газете «Фольксцайтунг», где авторы отмечают, что «уплата рабочим пособия за 3 месяца повышает расходы на наборные машины на 20 \%» [Колокольников, 1909, с. 50]. По их мнению, «когда правительство увеличивает пограничные пошлины на иностранные машины, его называют реакционным и говорят, что оно задерживает развитие промышленности, а тем самым культурное развитие страны. А здесь являются пролетарии и налагают пошлины на машины в $20 \%$ \% [Колокольников, 1909, с. 50],

Процесс технологического вытеснения рабочей силы наблюдается и в эпоху раннего СССР. В резолюции советского политического деятеля В.В. Куйбышева к одному из Всесоюзных съездов Советов содержится следующая мысль: «Неизбежное в отдельных предприятиях сокращение рабочей силы в связи с улучшением техники производства должно быть компенсировано более быстрым общим ростом промышленности. В планах развертывания промышленности должно предусматриваться повышение количества занятой рабочей силы, как во всей промышленности, так и в основных промышленных районах. В тех случаях, когда рационализация не может сопровождаться расширением данного предприятия, необходимо освободить его от образовавшихся излишков рабочей силы, выдавая увольняемым рабочим пособие в размере от полутора до трехмесячного заработка в зависимости от района» (цит. по: [Завьялов, 1927, с. 11]).

Отталкиваясь от приведенных фактов, можно предположить следующее. Уровень заработной платы является лишь одним из факторов, влияющих на решение о внедрении машины и, соответственно, на риск возникновения технологической безработицы. Исследование опыта Российской империи позволяет выделить и другой критерий, а именно снижение нормы прибыли экономических субъектов, в том числе в силу более высокого технологического развития других стран.

Об этом, в частности, говорит следующий факт, приведенный советским ученымэкономистом С.Г. Струмилиным: «Раньше других отраслей труда почувствовала свою отсталость после промышленного переворота в Англии русская металлургия, работавшая на английский рынок» [Струмилин, 1966, c. 391]. Первоначально предложенным выходом из ситуации стало усиление «строгости» в отношении подневольных рабочих с целью увеличения их производительности труда. Однако, как отмечает министр финансов граф Васильев еще в 1804 г., «возможная строгость вызывает лишь беспрерывное противоборство рабочих людей. Строгость принуждения делает работника унылым; унылость духа затмевает его способности, которые развязываются в одном непринужденном состоянии» [Струмилин, 1966, с. 392]. Вследствие этого в начале XIX в. становится ясным, что выход из сложившейся ситуации только через «строгость в отношении подневольных рабочих» без совершенствования техники будет невозможным [Струмилин, 1966, с. 392].

Не только прошедшие экономические эпохи, но и современный мир характеризуется выраженной непропорциональностью «машинного» развития. По данным Международной федерации робототехники, на сегодняшний день в России на 10 тысяч сотрудников приходятся 3 робота, тогда как аналогичный показатель, например, для Хорватии составляет 6, Японии - 303, Южной Кореи - лидера по данному критерию - 631 [Международная федерация ..., 2018]. Опыт Российской империи показывает, что совершенствование «строгости» в отношении рабочего класса бес- 
полезно и не является полноценным ответом на вызовы цифровой экономики. Из этого вытекает логичный вопрос: сможет ли современная Россия достойно ответить на новый исторический вызов, аналогичный британскому «промышленному перевороту» (например, в случае интенсивного развития технологий искусственного интеллекта), последствием которого станет существенная диспропорция в нормах прибыли без нанесения существенного ущерба рабочему классу?

На совещании по вопросам развития технологий в области искусственного интеллекта президентом РФ Владимиром Путиным был заявлен новый рецепт макроэкономического успеха: «тот, кто сможет обеспечить монополию в сфере искусственного интеллекта, тот станет властелином мира» [Совещание ... , 2019]. Однако на сегодняшний день Российской Федерации далеко до лидерства в области искусственного интеллекта. На это, например, указывает анализ статистических данных относительно количества компаний, работающих в сфере искусственного интеллекта, по разным странам (табл. 2).

Представленная таблица 2 позволяет сделать основной вывод, связанный с тем, что на сегодняшнем рынке искусственного интеллекта лидируют американские $(41,18$ \%) и китайские $(20,53 \%)$ компании. Далее с большим отрывом идут британские $(7,96 \%)$, канадские $(5,79 \%)$ и индийские $(3,09 \%)$ компании. К сожалению, российские компании крайне слабо представлены на мировом рынке технологий искусственного интеллекта $(0,35 \%)$ и уступают, например, Испании, Польше, Италии и т. д., что может низвести российскую экономику до «периферийного» уровня в среднесрочной перспективе.

Такая стратегия может быть губительной для общества, в частности рабочего класса, в случае широкого распространения зарубежных «трудосберегающих» технологий на российском рынке. Обратимся к анналам экономической истории, а именно к труду немецкого экономиста Фридриха Листа (17891846) «Национальная система политической экономии». Анализируя специфику экономического развития Северной Америки, автор утверждает, что открытие рынков для более дешевых английских мануфактурных товаров принесло стране «волнение и разорения», хотя ее возвеличивание случилось благодаря грамотно продуманным таможенным ограничениям [Лист, 2005, с. 23-24]. В свою очередь, к причине «благосостояния нации» России немецкий ученый относит «спасение в так осуждаемой теории протекционной системы» в силу неподготовленности страны к мануфактурной промышленности [Лист, 2005, с. 21, 23-24].

Резко усугубить ситуацию может и текущее положение рабочего класса в Российской Федерации. В 2019 г. международной консалтинговой компанией BCG было выпущено исследование относительно восприятия работниками технологий искусственного интеллекта в 30 странах, в том числе в Российской Федерации. Около 30 \% российских респондентов высказали сильную обеспокоенность в связи с возможной угрозой потери работы, в частности в государственном секторе, изза внедрения искусственного интеллекта. Более чем половиной респондентов был заявлен запрос на регулирование новых технологий в

\section{Количество компаний в сфере разработки технологий искусственного интеллекта}

в разных странах

\begin{tabular}{|l|c|r|}
\hline \multicolumn{1}{|c|}{ Государство } & $\begin{array}{c}\text { Количество } \\
\text { компаний }\end{array}$ & Доля \\
\hline США & 2028 & $41,2 \%$ \\
\hline Китай & 1011 & $20,5 \%$ \\
\hline Великобритания & 392 & $8 \%$ \\
\hline Канада & 285 & $5,8 \%$ \\
\hline Индия & 152 & $3,1 \%$ \\
\hline Россия & 1040 & $\mathbf{0 , 3} \%$ \\
\hline Другие & $41,1 \%$ \\
\hline \multicolumn{2}{|r|}{} \\
\hline
\end{tabular}

Примечание. Составлено автором по: [China ...]. 
целях защиты рабочих мест в России, а треть респондентов утверждает, что современная образовательная система не позволяет готовить детей к рынку труда в долгосрочной перспективе [Исследование ..., 2019],

Далее следует подчеркнуть, что, несмотря на достаточно высокий уровень участия работников в профсоюзах $(30,5 \%)$ [Statistics ...], согласно данным Международной конференции профсоюзов, в России наблюдаются «регулярные нарушения трудовых прав» [Report ...]. Наконец, в ситуации, когда на $3 \%$ российского населения приходится практически весь объем финансовых активов, срочных вкладов и наличных сбережений [Богатые граждане ... , 2019], весьма проблематичной выглядит возможность потенциального внедрения принципа «справедливого распределения выгод» в результате становления цифровой экономики.

\section{Выводы}

Таким образом, на основании изученного материала можно сделать следующий вывод. Капиталистическая форма производственных отношений не предусматривает многомерной заботы о рабочем классе, ограничиваясь нормативной выплатой денежного довольствия за проделанный труд. Такой подход обусловливает опасность «дисквалификации» рабочего класса в эпоху кардинальной смены технологического уклада и традиционных методов производства. В этих условиях во избежание необратимых рисков особую актуальность приобретает проблема формирования новых моделей социально-трудовых отношений в обществе. Международные институты целенаправленно занимаются работой по координированному совершенствованию социально-экономических отношений с учетом предсказуемых последствий развития цифровой экономики. Как показывает анализ, экономика РФ пока отстает в этом маневре от мировых тенденций. В контексте конкуренции стран за влияние на глобальной арене РФ необходимо в среднесрочной перспективе повысить проективную активность и изыскивать новые методологические принципы по гармонизации социально-экономических отношений с вызовами новой IT-среды.

\section{СПИСОК ЛИТЕРАТУРЫ}

Балабанов, М. С. От 1905 к 1917 году: массовое рабочее движение / М. Балабанов. - М. ; Л. : Гос. изд-во, 1927. -455 с.

Богатые граждане владеют фактически всеми финансовыми активами и сбережениями в РФ / / Коммерсант. - 2019. - 12 апр. - Электрон. текстовые дан. - Режим доступа: https:// www.kommersant.ru/doc/3940397 (дата обращения: 25.06.2019). - Загл. с экрана.

Богданов, А. А. Краткий курс экономической науки / А. А. Богданов. - Харьков : Гос. изд-во Украины, 1923. - 240 c.

Гулишамбаров, С. И. Сравнительная статистика России в мировом хозяйстве и в ряду великих держав 1894-1904 гг. II. Живой инвентарь, паровые двигатели, пути и средства сообщения / С. И. Гулишамбаров. - СПб. : Тип. «Северъ», 1907. -96 c.

Завьялов, В. И. Социалистическая рационализация производства и задачи экономической работы ВЛКСМ / В. И. Завьялов. - М. ; Л. : [б. и.], 1927. $-56 \mathrm{c}$.

Империализм и всеобщий кризис капитализма : paбочая кн. для вузов и комвузов / под. ред. Л. Кашарского, В. Серебрякова. - М. : ОгизГос. соц.-экон. изд-во, 1931. -653 с.

Исследование: россияне боятся потери работы изза искусственного интеллекта // РИА Новости. - 2019. - 13 марта. - Электрон. текстовые дан. - Режим доступа: https://ria.ru/20190313/ 1551739327.html (дата обращения: 25.06.2019). Загл. с экрана.

Колокольников, П. Н. Профессиональное движение и союзы в России / П. Н. Колокольников (К. Дмитриев, псевд.). - 2-е изд. - СПб. : Тип. товарищества «Екатерингоф. печ. дело», 1909. $-384 \mathrm{c}$.

Красильщиков, В. А. Вдогонку за прошедшим веком : Развитие России в XX в. с точки зрения мировых модернизаций / В. А. Красильщиков. - М. : РОССПЭН, 1998. - 263 с.

Кузнецов, А. Социализм и коммунизм / А. Кузнецов. - М. : Партиздат, 1929. - 144 с.

Лист, Ф. Национальная система политической экономии / Ф. Лист ; пер. В. А. Фадеева. - М. : Европа, 2005. -380 c.

Макушина, Л. В. Проблемы социально-трудовых отношений: поиск взаимоприемлемых решений / Л. В. Макушина // Согласие в обществе как условие развития современной России: политические и социальные аспекты : сб. науч. тр. - М. : [б. и.], 2011. - С. 238-247.

Маркс, К. Капитал. Критика политической экономии. Т. 1, кн. 1. Процесс производства капи- 
тала / К. Маркс. - М. : Политиздат, 1983. $3883 \mathrm{c}$.

Международная федерация робототехники представила список самых роботизированных стран мира // Rusbase. - 2018. - 4 мая. - Электрон. текстовые дан. - Режим доступа: https://rb.ru/ story/countries-with-greatest-density-of-robots/ (дата обращения: 25.06.2019). - Загл. с экрана.

Наказ Коммиссии о сочинении проэкта новаго уложения, с принадлежащими к тому приложениями. - М. : Сенат, 1767. $-118 \mathrm{c}$.

Работать ради лучшего будущего - Глобальная комиссия по вопросам будущего сферы труда // Международная организация труда. - Электрон. текстовые дан. - Режим доступа: https:// www.ilo.org/wcmsp5/groups/public/- dgreports/—-cabinet/documents/publication/ wcms_662472.pdf (дата обращения: 25.06.2019). - Загл. с экрана.

Смирнов, А. Д. Критика буржуазных и реформистских экономических теорий / А. Д. Смирнов. - М. : Высш. шк., 1969. - 426 с.

Совещание по вопросам развития технологий в области искусственного интеллекта // Президент России. - 2019. - 30 мая. - Электрон. текстовые дан. - Режим доступа: http:// kremlin.ru/events/president/news/60630 (дата обращения: 25.06.2019). - Загл. с экрана.

Струмилин, С. Г. Очерки экономической истории России и СССР / С. Г. Струмилин. - М. : Наука, 1966. -509 с.

Тихомиров, Л. А. В подполье : Очерки из жизни русских революционеров 70-80 гг. : пер. с фр. / Л. А. Тихомиров. - СПб. : Друг народа, 1907. $-176 \mathrm{c}$.

Туган-Барановский, М. И. Очерки из новейшей истории политической экономии / М. И. ТуганБарановский. - СПб. : Журн. «Мир божий», 1903. $-434 \mathrm{c}$.

Фабрично-заводская промышленность и торговля России (издание Департамента торговли и мануфактур Министерства финансов). - СПб. : Тип. В.С. Балашева и Ко, 1893. $-347 \mathrm{c}$.

Фиммен, Э. Буржуазная и пролетарская Европа / Э. Фимен ; пер. с нем. М. Розенфельд. - М. : Изд-во ВЦСПС, 1924. - 134 с.

Чупров, А. И. Курс политической экономии / А. И. Чупров. - М. : М. и С. Сабашниковы, 1916. -356 с.

China AI Development Report 2018// China Institute for Science and Technology Policy at Tsinghua University. - Electronic text data. - Mode of access: http://www.sppm.tsinghua.edu.cn/ eWebEditor/UploadFile/China_AI_development report_2018.pdf(date of access: 25.06 .2019$)$. Title from screen.
Forty-Two Countries Adopt New OECD Principles on Artificial Intelligence // OECD. - Electronic text data. - Mode of access: https://www.oecd.org/ science/forty-two-countries-adopt-new-oecdprinciples-on-artificial-intelligence.htm (date of access: 25.06.2019). - Title from screen.

Recommendation of the Council on OECD Legal Instruments Artificial Intelligence // OECD. Electronic text data. - Mode of access: https:// legalinstruments.oecd.org/api/print?ids= 648\&lang=en (date of access: 25.06.2019). - Title from screen.

Report - ITUC Global Rights Index 2019 // ITUC CSI IGB. - Electronic text data. - Mode of access: https://www.ituc-csi.org/IMG/pdf/2019-06-itucglobal-rights-index-2019-report-en-2.pdf(date of access: 25.06.2019). - Title from screen.

Research and Development Expenditure (\% of GDP) // The World Bank. - Electronic text data. - Mode of access: https://data.worldbank.org/indicator/ gb.xpd.rsdv.gd.zs (date of access: 25.06.2019). Title from screen.

Statistics and Databases // International Labour Organization. - Electronic text data. - Mode of access: https://www.ilo.org/global/statisticsand-databases/lang_en/index.htm (date of access: 25.06 .2019 ). - Title from screen.

\section{REFERENCES}

Balabanov M.S. Ot 1905 k 1917 godu: massovoe rabochee dvizhenie [From 1905 to 1917: Massive Labor Movement]. Moscow; Leningrad, Gosudarstvennoe Izd-vo, 1927. 455 p.

Bogatye grazhdane vladeyut fakticheski vsemi finansovymi aktivami i sberezheniyamiv RF [Rich Citizens Own All Financial Assets and Savings in the Russian Federation]. Kommersant, 2019, April 12. URL: https://www.kommersant.ru/doc/ 3940397 (accessed 25 June 2019).

Bogdanov A.A. Kratkiy kurs ekonomicheskoy nauki [Short Course of Economic Science]. Kharkov, Gosudarstvennoe izdatelstvo Ukrainy, 1923. $240 \mathrm{p}$.

Gulishambarov S.I. Sravnitelnaya statistika Rossii v mirovom khozyaystve i vryadu velikikh derzhav 1894-1904 gg. II. Zhivoy inventor, parovye dvigateli, puti $i$ sredstva soobshcheniya [Comparative Statistics of Russia in the World Economy and Among the Great Powers of 1894 1904. 2. Living Equipment, Steam Engines, Ways and Means of Communication]. Saint Petersburg, Tipografiya «Sever», 1907.96 p.

Zavyalov V.I. Sotsialisticheskaya ratsionalizatsiya proizvodstva i zadachi ekonomicheskoy raboty 
VLKSM [Socialist Production Rationalization and Economic Objectives of the All-Union Leninist Young Communist League]. Moscow; Leningrad, Molodaya Gvardiya Publ, 1927. 56 p.

Imperializm $i$ vseobshchiy krizis kapitalizma : rabochaya kn. dlya vuzov i komvuzov [Imperialism and the General Crisis of Capitalism. Working Book for Higher Education Institutions and Communistic Higher Education Institutions]. Moscow, Ogiz-Gosudarstvennoe sotsialno-ekonomicheskoe izdatelstvo, 1931. $653 \mathrm{p}$.

Issledovanie: rossiyane boyatsya poteri raboty iz-za iskusstvennogo intellekta [Research: Russians are Afraid of Losing Their Jobs Because of Artificial Intelligence]. RIA Novosti, 2019, March 13. URL: https://ria.ru/20190313/ 1551739327.html (accessed 25 June 2019).

Kolokolnikov P.N. Professionalnoe dvizhenie i soyuzy $v$ Rossii [Professional Movement and Unions in Russia]. Saint Petersburg, Tipografiya tovarishchestva «Ekateringofskoe pechatnoe delo», 1909. $384 \mathrm{p}$.

Krasilshchikov V.A. Vdogonku za proshedshim vekom : Razvitie Rossii v XXv. s tochki zreniya mirovykh modernizatsiy [In Pursuit of the Past Century. Development of Russia in the $20^{\text {th }} \mathrm{c}$. in Terms of World Modernization]. Moscow, ROSSPEN Publ., 1998. 263 p.

Kuznetsov A. Sotsializm i kommunizm [Socialism and Communism]. Moscow, Partizdat, 1929. 144 p.

List F. Natsionalnaya sistema politicheskoy ekonomii [National System of Political Economy]. Moscow, Evropa Publ., 2005. 380 p.

Makushina L.V. Problemy sotsialno-trudovykh otnosheniy: poisk vzaimopriemlemykh resheniy [Problems of Social and Labor Relations: Search for Mutually Acceptable Solutions]. Soglasie v obshchestve kak uslovie razvitiya sovremennoy Rossii: politicheskie i sotsialnye aspekty : sb. nauch. tr. [Consent in Society as a Condition for the Development of Modern Russia. Political and Social Aspects. Collection of Scientific Articles]. Moscow, 2011, pp. 238-247.

Marks K. Kapital. Kritika politicheskoy ekonomii. T. 1, kn. 1. Protsess proizvodstva kapitala [Capital. Criticism of Political Economy. Vol. 1, Book 1. Capital Production Process]. Moscow, Politizdat, 1983. 3883 p.

Mezhdunarodnaya federatsiya robototekhniki predstavila spisok samykh robotizirovannykh stran mira [International Federation of Robotics Presented the List of the Most Robotic-Aided Countries in the World]. Rusbase, 2018, May 4. URL: https://rb.ru/story/countries-with-greatestdensity-of-robots/ (accessed 25 June 2019).
Nakaz Kommissii o sochinenii proekta novago ulozheniya, s prinadlezhashchimi $k$ tomu prilozheniyami [Order of the Commission to Write a New Code Project with the Corresponding Appendices]. Moscow, Senat Publ., 1767. 118 p.

Rabotat radi luchshego budushchego - Globalnaya komissiya po voprosam budushchego sfery truda [Working for a Better Future - Global Commission on the Issues of Future of the World of Work]. Mezhdunarodnaya organizatsiya truda [International Labor Organization]. URL: https:/www.ilo.org/wcmsp5/groups/public/dgreports/—cabinet/documents/publication/ wcms_662472.pdf(accessed 25 June 2019).

Smirnov A.D. Kritika burzhuaznykh i reformistskikh ekonomicheskikh teoriy [Criticism of Bourgeois and Reformist Economic Theories]. Moscow, Vysshaya shkola Publ., 1969. 426 p.

Soveshchanie po voprosam razvitiya tekhnologiy v oblasti iskusstvennogo intellekta [Meeting on Developing Technologies in the Field of Artificial Intelligence]. Prezident Rossii [President of Russia], 2019, May 30. URL: http://kremlin.ru/ events/president/news/60630 (accessed 25 June 2019).

Strumilin S.G. Ocherki ekonomicheskoy istorii Rossii $i$ SSSR [Essays of the Economic History of Russia and the USSR]. Moscow, Nauka Publ., 1966. 509 p.

Tikhomirov L.A. V podpolye : Ocherki iz zhizni russkikh revolyutsionerov 70-80 gg. : per. s fr. [In the Hiding: Essays from the Life of Russian Revolutionaries of $70 \mathrm{~s}-80 \mathrm{~s}$. Translated from French]. Saint Petersburg, Drug naroda Publ., 1907. 176 p.

Tugan-Baranovskiy M.I. Ocherki iz noveyshey istorii politicheskoy ekonomii [Essays From The Recent History of Political Economy]. Saint Petersburg, Zhurnal «Mir bozhiy», 1903. $434 \mathrm{p}$.

Fabrichno-zavodskaya promyshlennost i torgovlya Rossii (izdanie Departamenta torgovli $i$ manufaktur Ministerstva finansov) [Factory and Plant Industry and Trade of Russia (Publication of the Department of Trade and Manufactures of the Ministry of Finance)]. Saint Petersburg, Tipografiya V.S. Balasheva i Ko, 1893.347 p.

Fimmen E. Burzhuaznaya i proletarskaya Evropa [Bourgeois and Proletarian Europe]. Moscow, Izd-vo VTsSPS, 1924. 134 p.

Chuprov A.I. Kurs politicheskoy ekonomii [Couse of Political Economy]. Moscow, M. i S. Sabashnikovy, 1916.356p.

China AI Development Report 2018. China Institute for Science and Technology Policy at Tsinghua University. URL: http://www.sppm.tsinghua. 
А.Б. Берберов. Феномен технологической безработицы

edu.cn/eWebEditor/UploadFile/China_AI development_report_2018.pdf(accessed 25 June 2019).

Forty-Two Countries Adopt New OECD Principles on Artificial Intelligence. OECD. URL: https:// www.oecd.org/science/forty-two-countriesadopt-new-oecd-principles-on-artificialintelligence.htm (accessed 25 June 2019).

Recommendation of the Council on OECD Legal Instruments Artificial Intelligence. $O E C D$. URL: https://legalinstruments.oecd.org/api/print?ids= 648\&lang=en (accessed 25 June 2019).
Report - ITUC Global Rights Index 2019. ITUC CSI IGB. URL: https://www.ituc-csi.org/IMG/pdf/ 2019-06-ituc-global-rights-index-2019-report-en2.pdf (accessed 25 June 2019).

Research and Development Expenditure (\% of GDP). The World Bank. URL: https://data.worldbank. org/indicator/gb.xpd.rsdv.gd.zs (accessed 25 June 2019).

Statistics and Databases. International Labour Organization. URL: https://www.ilo.org/global/ statistics-and-databases/lang-en/index.htm (accessed 25 June 2019).

\section{Information about the Author}

Azamat B. Berberov, Postgraduate Student, Department of Economic Theory, Financial University under the Government of the Russian Federation, Leningradskiy Prosp., 49, 125993 Moscow, Russian Federation, berberro@yandex.ru, https://orcid.org/0000-0003-2739-8912

\section{Информация об авторе}

Азамат Бурханович Берберов, аспирант департамента экономической теории, Финансовый университет при Правительстве РФ, Ленинградский просп., 49, 125993 г. Москва, Российская Федерация, berberro@yandex.ru, https://orcid.org/0000-0003-2739-8912 